\title{
CORRESPONDENCE
}

\section{PRESSURE IN THE CANAL OF SCHLEMM}

\section{To the Editorial Committee of the British Journal of OpHThalmology,}

DeAR SIRS-In the April number Mr. E. S. Perkins published an interesting paper on the pressure in Schlemm's canal (Perkins, 1955). He came to the conclusion that in normal man there exists practically no difference in pressure between the anterior chamber and the canal of Schlemm; this means that the resistance of the corneo-scleral trabeculae is insignificant compared with the resistance of the episcleral outlets. These conclusions are based on:

(1) studies of the pressure in cannulas introduced into Schlemm's canal, in which experiments, however, he himself does not place much reliance;

(2) experiments prompted by W.M. Grant of Boston, Mass.

In this second set of experiments Perkins measured the outflow from the anterior chamber before and after exposing the canal of Schlemm by sectioning the cornea layer by layer in an enucleated human eye, in an enucleated monkey eye, and in a living monkey eye. It was confirmed by histological examination that in all these experiments the trabeculae were not injured. Perkins's data were as follows:

\begin{tabular}{ll|c|c|c}
\hline \multicolumn{1}{c|}{ Eye } & & $\begin{array}{c}\text { Pressure } \\
\text { (cm. saline) }\end{array}$ & Initially & $\begin{array}{c}\text { After opening } \\
\text { Schlemm's Canal }\end{array}$ \\
\cline { 3 - 4 } & & $57 \cdot 5$ & $4 \cdot 59$ & $15 \cdot 5$ \\
Enucleated human & $\ldots$ & 25 & $16 \cdot 0$ & $37 \cdot 7$ \\
Lnucleated monkey & $\ldots$ & 25 & $13 \cdot 5$ & $51 \cdot 66$ \\
\hline
\end{tabular}

At first glance Perkins's conclusions seem to be right, but if one considers these experiments more critically and mathematically the results are different. The aqueous humour of an enucleated eye flows out through the bisected episcleral and conjunctival veins in which the pressure must be zero. The pressure of outflow, which in the living eye is equal to the intra-ocular tension minus the episcleral venous pressure (9 to $10 \mathrm{~mm}$.), will therefore be equal to the tension in the enucleated eye. The very similar results of fluorometry (Goldmann, 1949) and tonography (Grant, 1954) have shown that the volume per minute of outflow from the human eye with an average outflow pressure of 6 to $7 \mathrm{~mm}$. $\mathrm{Hg}$ is of the order of 2 to $2.5 \mathrm{~mm}^{3}$. In Perkins's experiment on an enucleated human eye under a pressure of $42.6 \mathrm{~mm}$. $\mathrm{Hg}, 4.6 \mathrm{~mm}^{3}$. of fluid left the anterior chamber; this means that the resistance in the system of outlets of this normal eye is much higher than in the living eye. Why is this so? The corneo-scleral trabeculae seem to be very rigid (results of tonography), but the episcleral and conjunctival venous system collapses in the enucleated eye. We have therefore to investigate the difference of pressure which allows an escape of 2 to $3 \mathrm{~mm} .^{3}$ after opening the canal of Schlemm. If the three experiments of Perkins are reliable this value is comparable to the decrease in pressure between the anterior chamber and the canal of Schlemm in the living eye. But since, in these conditions with an intra-ocular tension of $42.6 \mathrm{~mm}$. $\mathrm{Hg}, 15.5 \mathrm{~mm} .^{3}$ of fluid flow out per minute, 
it follows that $2 \cdot 3 \mathrm{~mm} \cdot{ }^{3}$ will leave the anterior chamber under a pressure of $6 \cdot 5 \mathrm{~mm} . \mathrm{Hg}$. As mentioned above, the pressure of outflow in the living human eye has been found to be 6 to $7 \mathrm{~mm}$. $\mathrm{Hg}$, which is exactly the same value as that found by Perkins. One must not overestimate this agreement on account of other differences between the living and the excised eye (e.g. temperature, fluid viscosity).

For the same reason we can say that in the enucleated monkey eye the decrease in pressure between the anterior chamber and the canal of Schlemm must be more than $\mathbf{4 0}$ per cent. of the total decrease. This value follows directly from the data of Perkins's second experiment.

In his third experiment on a living monkey eye the same calculation shows that $60-75$ per cent. of the total decrease in pressure is due to the resistance in the trabeculae provided we take 9 to $10 \mathrm{~mm}$. $\mathrm{Hg}$ as the pressure of the episcleral venous system and 2 to $4 \mathrm{~mm} \cdot 3 / \mathrm{min}$. for the rate of flow (data from human and rabbit eyes).

Perkins's second set of experiments therefore offers no proof for his conclusions that the resistance in the corneo-scleral trabeculae of man can be neglected. As far as I am concerned I rather think that they prove the contrary.

Yours faithfully,

\section{H. Goldmann.}

Freiburgstrasse, 8,

Berne, SwitzerLand.

August 16, 1955.

\section{REFERENCES}

GoldmanN, H. (1949). Trans. ophthal. Soc. U.K., 69, 455.

Grant, W. M. (1954). Personal communication.

Perkins, E. S. (1955). British Journal of Ophthalmology, 39, 215.

\section{To the Editorial Committee of the British Journal of Ophthalmology,}

Sirs-I was most interested to read Professor Goldmann's letter and I am grateful for an opportunity of replying to it.

Professor Goldmann's figures are of course perfectly correct, providing his assumptions are also correct for the conditions of the experiments, but if I may quote from my paper: "In these experiments (i.e. the flow measurements) only a small opening has been made into the canal so that it is not justifiable to make mathematical deductions from the figures obtained".

In no part of my paper did I suggest that the resistance of the corneo-scleral trabeculae can be neglected-again quoting from the paper: "The results do indicate that there is a considerable resistance to flow between the canal of Schlemm and the venous system "a conclusion which I am glad to find confirmed by Professor Goldmann's own figures, i.e. 25-40 per cent. in the living monkey eye, and 60 per cent. in the dead monkey eye.

With regard to the direct measurement of the pressure in the canal of Schlemm, I am confident that the experimental findings are correct and that they will be confirmed when more is known about these pressure relationships.

Yours faithfully,

E. S. Perkins.

INSTITUTE OF OPHTHALMOLOGY,

JudD ST., LONDON, W.C.1.

August 23, 1955. 